\title{
Effect of perceived safety, procedural justice on domestic airline passengers of Nigeria
}

\author{
Muhammad Haliru \\ Sany Sanuri Mohd Mokhtar \\ University Utara Malaysia, Malaysia
}

Keywords

Service recovery, procedural justice, perceived safety and Nigeria's domestic airline.

\begin{abstract}
The aim of the paper is to empirically examine how perceived safety and procedural justice effect satisfaction service recovery of domestic airline passengers in Nigeria. The study uses survey method, quantitative in nature. Using PLS SEM the conceptual model was tested with a sample of 444 passengers obtained through cluster sample. From the result, both perceptions of safety and procedural justice are important to domestic airline passenger satisfaction when evaluating the airline's recovery effort in Nigeria. Empirical evidence showed that satisfaction service recovery is directly influenced by perceived safety and procedural justice.

The main limitation is that the study uses cross-sectional sample of airline passengers. It also relied on information from prospective domestic airline passengers, while neglecting other type of passengers. The research shows that passengers' perception of safety, determine their satisfaction with service recovery. It shows that in situations of failure similar to the present, safety perception, procedural justice should be given preference during service recovery.

The study fortifies the justice theory in service recovery of domestic airline context by including perception of safety. However, through empirical testing the perception of safety, procedural justice variables determine satisfaction with recovery. It suggests that airline industry faced with service failure need to consider the passengers' perception of safety and procedural justice during recovery.
\end{abstract}

Corresponding author: Muhammad Haliru

Email address for corresponding author: muhammadhaliru214@gmail.com

First submission received: 4th April 2017

Revised submission received: 15th May 2017

Accepted: 20th July 2017

\section{Introduction}

Service firms try every single effort to deliver error free service, in order to amplify satisfaction of customer and advance continuing customer relationship. Consequently, even for the finest firms, mistakes do occur during service delivery procedure. Resultantly, effective service recovery is needed for relationship building and customer retention. Bitner, Booms, and Tetreault, (1990) showed that most customers can tolerate some service mistakes and mistakes alone do not lead to dissatisfaction. But refusal to take service recovery measures is the primary reason for customer dissatisfaction. Therefore, it is important that when mistakes happen, remedial measures need to be taken by service firms to effectively turn unhappy customers into pleased ones (Gursoy et al. 2005). Numerous studies shows that failure in service recovery is a vital reason for customer loss; while successful service recovery can increase customer satisfaction and retention (Maxham and Netemeyer, 2002).

Equally, managers and researchers recognized the significance of service recovery. Consequently, considerable research has been carried out on effectiveness, features of service recovery and its influence on customers. Specifically, studies like Bitner et al. (1990) use critical incident examination to assess customers' service consumption experience and summarize the attributes of service recovery. Recently also, scholars like (Tax et al. 1998; Wagner et al. 1999) 
examine the customers' assessment of service recovery using justice theory. The theory has provided a robust theoretical foundation for service recovery research and to a certain extent noteworthy findings has been deduced from the studies. Blodgett et al. (1997) found interactional and distributive justices significantly show more variance than procedural justice, while Smith et al. (1999) proves that higher fairness is to distributive and procedural justices.

The existing literature is intended to be extended by the current study through the investigation of how perception of safety, procedural justice could influence satisfaction service recovery. A model was conceptually proposed to examine the influence of perceived safety, and procedural justice on satisfaction service recovery of domestic airline passenger. Additionally, a lot of preceding studies implemented experimental/scenario-based method in which irrelevant variable influences were controlled. They also lack external validity; they therefore will not be universally applicable. To overcome, the mentioned problems the conceptual model using data collected from prospective domestic airline passengers of Abuja and Lagos airports is tested. Passengers expect quality service recovery performance that will lead them to become satisfied with the recovery process. Service failures such as flight cancellations, loss of baggage, staff attitude (ground and cabin), and air strikes (Bamford \& Xystouri 2005) or mishap could have effect on satisfaction of passenger, and we argue that the steps taken with consideration to perception of safety, fair procedural justice during recovery from failure will subsequently affect passengers' satisfaction with the recovery.

\section{Conceptual background.}

Regardless of efforts to strategize on service delivery procedure to be as free from error as possible (Shostack 1984; Chase \& Stewart 1994), people involvement and its intangibility make service failure prevention difficult (Hart et al. 1990; Dewitt et al. 2003; Dong et al. 2008). Service failure creates undesirable customer responses (Keaveney 1995). Substantial scholars' attention has focused on developing strategies to recover from service failures in order to reduce these negative consequences (Miller et al. 2000; Davidow 2003). However, the findings of previous studies vary, for instance McCollough, Berry, and Yadav, (2000) studied customer satisfaction after service failure and recovery by means of scenario-based experiment and institute that distributive and interactional justice are important predictors of post recovery satisfaction, while in contrast Wagner et al., (1999) initiate that all the three justices together explain high satisfaction after service recovery or by either different antecedents or variables. Hence, re-evaluation of service recovery is critical in gaining a profound understanding of effective strategies for service recovery; this paper considers how perception of safety influences satisfaction service recovery.

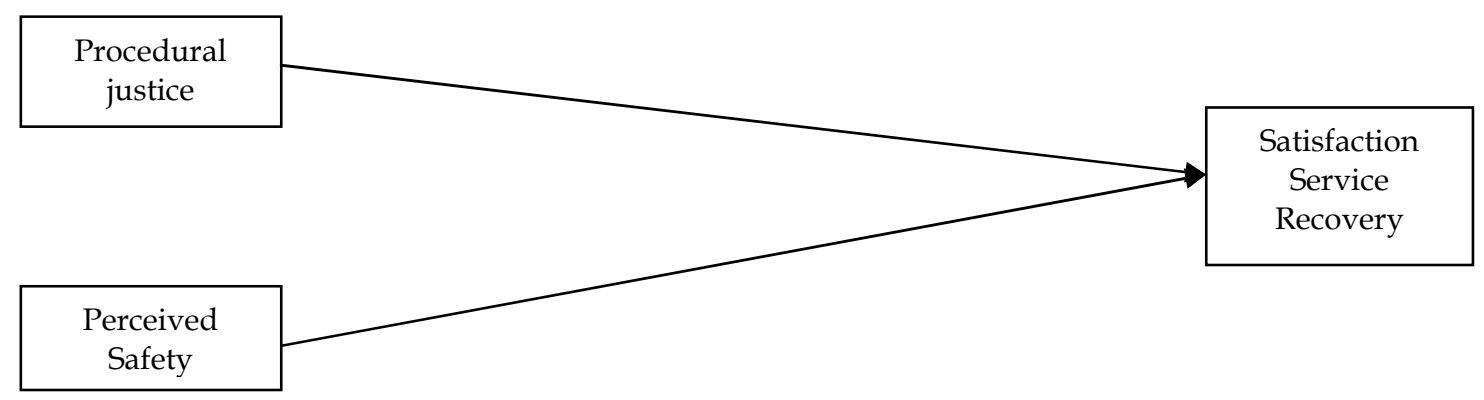

\section{Literature review and hypothesis}

Figure 1: Conceptual model

\subsection{Procedural Justice}

Procedural justice consists of customer assessments of whatever processes were employed to bring about a resolution in any service failure situation (Thibaut \& Walker, 1975; Lind \& Tyler, 1988). 
In particular, it is concerned with the fairness of the measures and procedures employed to reach any recovery result (Blodgett et al. 1997). In assessing procedural justice fairness customers include their perceptions of policies and procedures, consideration of service recovery elements such as the ability to be altered (flexibility) and act in response speedily and absolutely (responsiveness) of the organization as a whole throughout the course of the recovery (Hoffman et al. 2003; Mccoll-kennedy et al. 2003; Chebat \& Slusarczyk 2005; Gustafsson 2009).

In other words, procedural justice denotes to the assessment of the technique used to come up with outcomes, or more specifically, the strategies and measures used to bring about the recovery result (Lind and Tyler 1988; Thibaut and Walker 1975). It is useful and meaningful as it aims to resolve conflict, with continued relationship even when outcomes are not satisfactory. Since the service process is often times an integral part of the entire product or service offering (Bitner et al. 1990), firms could presumably benefit from establishing procedural justice during the recovery effort, and the effect seems likely for satisfaction with the recovery. Several studies supports the impact of procedural justice (Mccoll-kennedy et al. 2003; Chebat \& Slusarczyk 2005; Gustafsson 2009). Based on the above, we hypothesized that:

H1 Procedural justice has a positive influence on satisfaction service recovery.

\subsection{Perceived Safety}

Perception of safety is an overlapping emotion of concern, panic and nervousness felt while experiencing an anxiety producing situation like air mishap (Hosany \& Gilbert 2009; Richins 1997). The occurrence of accidents cannot be eradicated completely, passengers are conscious of this fact. The perceived risk is assumed as the subjective anticipation of a loss (Sweeney et al. 1999)which creates feeling of uncertainty, uneasiness, and nervousness (Dowling \& Staelin 1994). Airlines try to limit the risks related to air travel through various safety measures that includes service quality (Rhoades \& Waguespack,1999).Flight safety based on aircraft appearance, pilot competence (Ringle,Sarstedt\&Zimmermann,2011).

Particularly, as assessment shape passengers' perception of safety, which is regarded as important criteria when choosing an airline could enhance their satisfaction. We therefore hypothesize that safety measures have a positive influence on customer satisfaction.

H2 Perceived Safety positively influence satisfaction service recovery

\subsection{Satisfaction service recovery}

Satisfaction with service recovery has been deliberated to be something serious for service firms in sustaining positive relationships with customers after service failure (Maxham, 2001; Maxham and Netemeyer, 2002; Stauss, 2002). Service failure and recovery encounter often arouse robust emotional responses from customers, which may influence customers' resolution of whether to carry on in a relationship with a company directly or indirectly. Satisfaction with service recovery mostly, however, taps the cognitive aspects of consumer behavior (expectations, disconfirmations, and justice perception) (McColl-Kennedy et al., 2003; Smith et al., 1999; Wirtz and Mattila, 2004).

Previous research suggests that emotional responses to service failure and subsequent recovery influence customer affection. Affection is distinct from customers' emotional responses in that customer affection is engendered and further reinforced or damaged by customers' emotional reactions in response to service recovery efforts. With perception of safety, the emotion of passenger will become positive thereby increase satisfaction with service recovery. Respectively, customers' emotional responses to service failure and recovery encounters have received some attention (Weiss et al., 1999; Chebat and Slusarczyk, 2005; DeWitt et al., 2008; Namkung and Jang, 2010).

\section{Methodology}

\subsection{Sample and data collection}

The study use survey method, to collect data cross-sectional, from domestic airline passengers of MM Airport, Lagos and Abuja International Airport.505 questionnaires were administered at the 
departure hall of both Airports through cluster sampling method. However, only 444of the administered questionnaires were filled and returned.53 questionnaires were excluded because multivariate outliers and missing data leaving 391 effective validresponses.77\% response rate achieved. Measures of satisfaction service recovery adapted from (McCollough et al., 2000; Nikbin, Marimuthu, Hyun, \& Ismail, 2014).Procedural justice adapted from(Wagner et al. 1999; Maxham\&Netemeyer,2003). Perceived safety adapted from (Ringle, Sarstedt \& Zimmermann, 2011). Item measures were based on a 5 point Likert Scale, ranging from $1=$ strongly disagree to $5=$ strongly agree.

\subsection{Model Estimation}

Preliminary analysis and data screening was conducted. Precisely, missing values and outliers were assessed. Normality and multicollinearity tests were also conducted without any severe issue. Similarly, the non-response bias result proposes that we progress with data analysis. Structural equation modelling Smart PLS (Hock, Ringle,\&Sarstedt, 2010)was used to evaluate both measurement and structural models. PLS a variance based SEM technique was chosen based on the consideration of complexity of the research model (Chin, 2010).

The Cronbach's Alpha, composite reliability, convergent and discriminant validity were considered in assessing the measurement model's internal consistency. The Cronbach's Alpha coefficients range between 0.59 and 0.81 while composite reliability coefficients range between 0.78 and 0.86 . Higher than the threshold of 0.70 this indicates adequate internal consistency reliability of measures (Nunnally, 1978).Factor loadings were also adequate as they range between 0.59 and 0.81.To achieve the model fit, 4 items whose outer loadings fall below0.7 were deleted(Chin, 2010) to arrive at the revised model. Convergent and discriminant validity of the instruments were evaluated through the approaches developed in PLS context by Fornell and Larcker (1981). Accordingly, the AVE of each latent construct was above 0.5 indicating adequate convergent and discriminant validity. Further, as suggested by Fornell \& Larcker (1981) the square root of the AVE to be higher than the correlations among the latent variables have been achieved also. As per table 2.

Table 1:

\begin{tabular}{lccc}
\hline Construct & Procedural Justice & Perceived Safety & Satisfaction Service Recovery \\
\hline PROC03 & $\mathbf{0 . 5 2 6 5 4 8}$ & 0.19095 & 0.254879 \\
PROC04 & $\mathbf{0 . 8 5 3 0 3 9}$ & 0.460629 & 0.499806 \\
PROC05 & $\mathbf{0 . 8 0 9 6 3}$ & 0.338689 & 0.436446 \\
PS01 & 0.347621 & $\mathbf{0 . 7 6 4 0 6 1}$ & 0.524695 \\
PS02 & 0.339662 & $\mathbf{0 . 7 0 6 4 2 1}$ & 0.490798 \\
PS03 & 0.34773 & $\mathbf{0 . 7 4 7 0 2 8}$ & 0.468388 \\
PS04 & 0.348246 & $\mathbf{0 . 6 7 2 7 7 3}$ & 0.469277 \\
PS06 & 0.341028 & $\mathbf{0 . 7 9 6 7 0 5}$ & 0.573125 \\
PS07 & 0.30411 & $\mathbf{0 . 6 4 1 9 6 2}$ & 0.500109 \\
SSR01 & 0.458114 & 0.602426 & $\mathbf{0 . 7 6 9 1 7 9}$ \\
SSR02 & 0.376263 & 0.511339 & $\mathbf{0 . 7 5 3 1 3 2}$ \\
SSR03 & 0.35427 & 0.556745 & $\mathbf{0 . 7 6 5 6 8 8}$ \\
SSR04 & 0.442866 & 0.426753 & $\mathbf{0 . 7 3 3 4 4 5}$ \\
SSR05 & 0.369072 & 0.409261 & $\mathbf{0 . 5 8 5 1 9 9}$ \\
\hline
\end{tabular}

Item cross loadings 
Table 2:

\begin{tabular}{llcr}
\hline Construct & AVE & Composite Reliability & Cronbachs Alpha \\
\hline Perceived Safety & 0.523392 & 0.867605 & 0.816187 \\
Procedural Justice & 0.553476 & 0.781553 & 0.590338 \\
Satisfaction Service Recovery & 0.525104 & 0.845636 & 0.771189 \\
\hline
\end{tabular}

Figure: 2

Average Variance Extracted, Composite reliability, and Cronbach`s Alpha

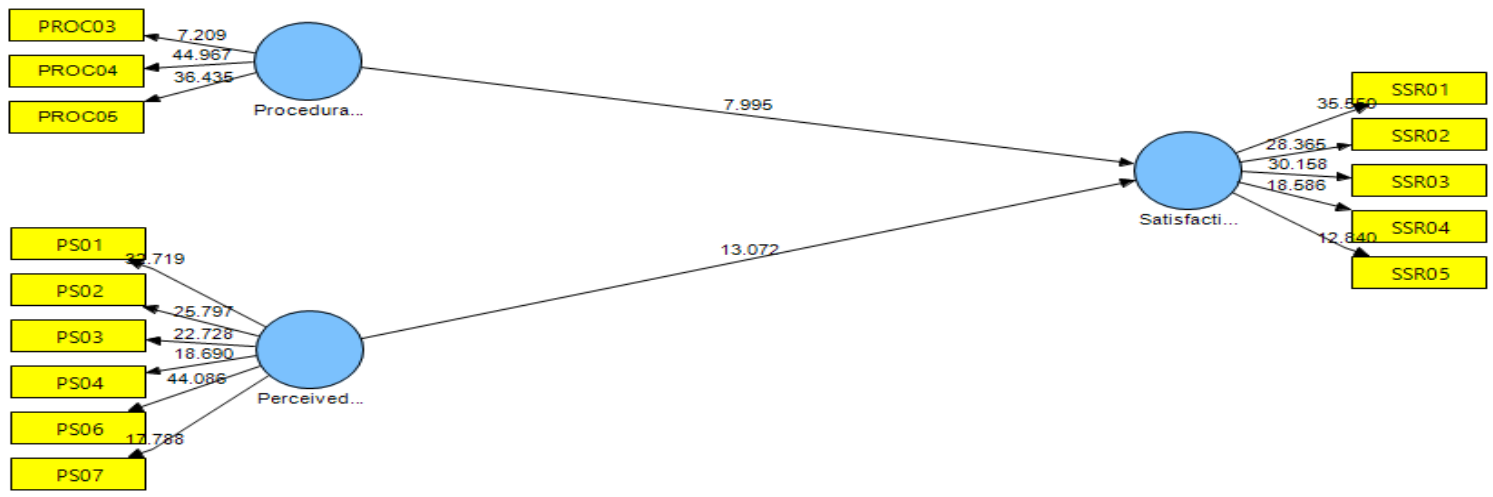

Structural Model

The structural model was assessed by applying the boot strapping procedure with 500 bootstrap samples and 391cases to examine the significance of the path coefficients (Chin, 2010).

Table 3: Result of Hypothesis testing

\begin{tabular}{|c|c|c|c|c|c|c|c|}
\hline & $\begin{array}{l}\text { Original } \\
\text { Sample } \\
(\mathrm{O})\end{array}$ & $\begin{array}{l}\text { Sample } \\
\text { Mean } \\
(\mathrm{M})\end{array}$ & $\begin{array}{l}\text { Standard } \\
\text { Deviation } \\
(\mathrm{STDEV})\end{array}$ & $\begin{array}{l}\text { Standard } \\
\text { Error } \\
\text { (STERR) }\end{array}$ & $\begin{array}{l}\text { T Statistics } \\
(\mid \mathrm{O} / \mathrm{STER} \\
\mathrm{R} \mid)\end{array}$ & $\begin{array}{c}\mathrm{P} \\
\text { value }\end{array}$ & Decision \\
\hline $\begin{array}{l}\text { Perceived Safety -> } \\
\text { Satisfaction Service } \\
\text { Recovery } \\
\text { Procedural Justice - } \\
\text { > Satisfaction }\end{array}$ & 0.565 & 0.567 & 0.043 & 0.043 & 13.072 & 0.000 & Supported \\
\hline Service Recovery & 0.289 & 0.290 & 0.036 & 0.036 & 7.995 & 0.000 & Supported \\
\hline Table 4: Effect & & & & & & & \\
\hline \multicolumn{8}{|l|}{ Construct } \\
\hline & \multicolumn{3}{|c|}{$\mathrm{R}$ square Included } & Excluded & f-squared & \multicolumn{2}{|c|}{ Effect size } \\
\hline Procedural justice & \multicolumn{2}{|c|}{0.55571} & \multicolumn{2}{|r|}{0.494} & 0.138896 & \multicolumn{2}{|c|}{ Small } \\
\hline Perceive safety & \multicolumn{2}{|c|}{0.55571} & \multicolumn{2}{|r|}{0.311} & 0.550789 & \multicolumn{2}{|c|}{ Large } \\
\hline
\end{tabular}

\section{Result}

The hypothesized significant positive relationship between procedural justice and satisfaction service recovery ( $\mathrm{u}=0.036, \mathrm{t}=7.955, \mathrm{p}<0.000$ ). Perceived safety and satisfaction service recovery (ü=0.043, $\mathrm{t}=13.072, \mathrm{p}<0.000$ ), were all supported. Consistent with prior research on the significant relationship between procedural justice and satisfaction service recovery(Ok et al. 2005). Perceived safety and satisfaction (Ringle et al., 2011). 


\section{Discussions}

The research was to validate a model for the domestic airline sector, and to particularly evaluate the influence of perceived safety and procedural justice on satisfaction service recovery. It is not unexpected to find that there is a significant relationship between the independent variables because safety issues like proper check on pilot competence, safety check of aircraft and its appearance should naturally enhance passenger satisfaction with service recovery. Procedural Justice issues are as well understood to influence the satisfaction of aggrieved passengers' satisfaction with the recovery process as suggested by Ok, Back, and Shanklin, (2005) that showed procedural justice of restaurant customer had greater influence on satisfaction service recovery than the other two justices.

The study provides significant insight into perceived safety, procedural justice, on satisfaction service recovery. Therefore, if a passenger perceived safety, he will continue with relationship despite the service failure (Ringle et al., 2011).

\section{Theoretical Implications}

The research contributes to theory by empirically validating the role of perceived safety as a construct that is scant in justice theory research. Procedural justice, perceived safety and outcome variable of satisfaction service recovery is empirically validated. Precisely, the outcome of our research theoretically contributes to the literature on service recovery in particular and services marketing in general.

\section{Managerial Implications}

The study findings suggest that to achieve passengers' satisfaction service recovery, it is necessary to be aware of safety perception influence on satisfaction service recovery of domestic airline passenger. That can be achieved through proper check on pilot competence, check on safety of the aircraft and its appearance (as proposed by Ringle et al., 2011).There must also be clear, convincing procedural justice Ok, Back, and Shanklin, (2005). Impliedly, passengers' procedural justices, perceived safety increases passengers' satisfaction with service recovery, which in turn enhances their relationship with domestic airlines, thus making airlines to operate at a profit.

\section{Limitations and future research direction}

Beside the contribution of the study, it should be interpreted with its limitations. Firstly, the data for the study was cross- sectional. In the future, studies should try longitudinal designs given the fact that customer perception and attitude changes with time. Second, the study investigated data from domestic airline passengers' future studies should consider passengers of International airlines. The variances of $56 \%$ indicate that several other factors also account for satisfaction service recovery in domestic airline services. Thus, the effects of constructs like controllability, purpose of travel, forgiveness and possibly the role of culture should be examined by future studies.

\section{Conclusions}

The present research consistent with the hypotheses, establishes that it will be of benefit for domestic airlines to improve on perception of safety during service recovery situations, in view of the enormous challenges of service failure facing the Nigeria domestic airline sector. Managers of domestic airline would benefit immensely from the insights regarding drivers of satisfaction in service recovery. Improve their financial performance through passenger satisfaction and retention.

\section{References}

Bamford, D. \& Xystouri, T., 2005. A case study of service failure and recovery within an international airline. Managing Service Quality, 15(3), pp.306-322.

Bitner, M., Booms, B. \& Tetreault, M., 1990. The service encounter: diagnosing favorable and unfavorable incidents. The Journal of Marketing. 
Blodgett, J.G., Hill, D.J. \& Tax, S.S., 1997. The effects of distributive, procedural, and interactional justice on post complaint behavior. Journal of Retailing, 73(2), pp.185-210.

Chase, R.B. \& Stewart, D.M., 1994. Make Your Service Fail-Safe. Sloan Management Review, 35(3), pp.35-44. Available at: http:// sloanreview.mit.edu/article/make-your-service-failsafe/.

Chebat, J.C. \& Slusarczyk, W., 2005. How emotions mediate the effects of perceived justice on loyalty in service recovery situations: An empirical study. Journal of Business Research, 58(5), pp.664673.

Davidow, M., 2003. Organizational Responses to Customer Complaints: What Works and What Doesn't. Journal of Service Research, 5(3), pp.225-250.

Dewitt, T., Brady, M.K. \& Brady, M.K., 2003. Journal of Service Research.

Dong, B., Evans, K.R. \& Zou, S., 2008. The effects of customer participation in co-created service recovery. Journal of the Academy of Marketing Science, 36(1), pp.123-137.

Dowling, G.R. \& Staelin, R., 1994. A Model of Perceived Risk and Intended Risk-Handling Activity. Journal of Consumer Research, 21(1), p.119.

Greenberg, 1990. Looking fair vs. being fair: Managing impressions of organizational justice. Research In Organizational Behavior, 12, pp.111-157. Available at:

http://www.mendeley.com/research/managing-impressions-keeping-garden/.

Gursoy, D., Chen, M.H. \& Kim, H.J., 2005. The US airlines relative positioning based on attributes of service quality. Tourism Management, 26(1), pp.57-67.

Gustafsson, A., 2009. Customer satisfaction with service recovery. Journal of Business Research, 62(11), pp.1220-1222.

Hart, C.W., Heskett, J.L. \& Sasser, W.E., 1990. The profitable art of service recovery. Harvard business review, 68(4), pp.148-156.

Hock, C., Ringle, C.M. \& Sarstedt, M., 2010. Management of multi-purpose stadiums: importance and performance measurement of service interfaces. International Journal of Services Technology and Management, 14(2/3), p.188.

Hoffman, K.D., Kelley, S.W. \& Chung, B.C., 2003. A CIT investigation of servicescape failures and associated recovery strategies. Journal of Services Marketing, 17(4), pp.322-340.

Hosany, S. \& Gilbert, D., 2009. Dimensions of Tourists 'Emotional Experiences towards Hedonic Holiday Destinations Copyright (C) S . Hosany and D . Gilbert ISBN : 978-1-905846-35-1,

Keaveney, S.M., 1995. Customer Switching Behavior in Service Industries: Journal of Marketing, 59(April), pp.71-82.

Maxham, J.G. \& Netemeyer, R.G., 2003. Firms Reap What They Sow: The Effects of Shared Values and Perceived Organizational Justice on Customers' Evaluations of Complaint Handling. Journal of Marketing, 67(1), pp.46-62.

Maxham, J.G. \& Netemeyer, R.G., 2002. Modeling customer perceptions of complaint handling over time: The effects of perceived justice on satisfaction and intent. Journal of Retailing, 78(4), pp.239-252.

Mccoll-kennedy, J.R. et al., 2003. Application of Fairness Theory to Service Failures and Service Recovery.

McCollough, M. a., Berry, L.L. \& Yadav, M.S., 2000. An Empirical Investigation of Customer Satisfaction after Service Failure and Recovery. Journal of Service Research, 3(2), pp.121-137.

Miller, J., Craighead, C. \& Karwan, K., 2000. Service recovery: a framework and empirical investigation. Journal of operations Management, 18(4), pp.387-400. Available at: http:/ / linkinghub.elsevier.com/retrieve/pii/S0272696300000322\nhttp:/ / www.sciencedirect. com/science/article/pii/S0272696300000322.

Nikbin, D. et al., 2014. Effects of Stability and Controllability Attribution on Service Recovery Evaluation in the Context of the Airline Industry. Journal of Travel $\mathcal{E}$ Tourism Marketing, 31(7), pp.817-834.

Ok, C., Back, K.J. \& Shanklin, C.W., 2005. Modeling Roles of Service Recovery Strategy: A 
Relationship-Focused View. Journal of Hospitality \& Tourism Research, 29(4), pp.484-507.

Rhoades, D.L. \& Waguespack, B., 1999. Better safe than service? The relationship between service and safety quality in the US airline industry. Managing Service Quality, 9(6), pp.396-401.

Richins, M.L., 1997. Measuring Emotions in the Consumption Experience. Journal of Consumer Research, 24(2), pp.127-146.

Ringle, C.M., Sarstedt, M. \& Zimmermann, L., 2011. Customer Satisfaction with Commercial Airlines: The Role of Perceived Safety and Purpose of Travel. The Journal of Marketing Theory and Practice, 19(4), pp.459-472.

Shostack, G.L., 1984. Designing services that deliver. Harvard business review, 62(1), pp.133-139. Available at:

http://demos.aptaracorp.com/Showcase/Courses/eLearning/Soft_Skills/HBSP_Service_Success/ module03/reading/pdfs/des_article.pdf.

Sweeney, J.C., Soutar, G.N. \& Johnson, L.W., 1999. The role of perceived risk in the quality-value relationship: A study in a retail environment. Journal of Retailing, 75(1), pp.77-105. Available at: http://www.sciencedirect.com/science/article/pii/S0022435999800050.

Tax, S.S., Brown, S.W. \& Chandrashekaran, M., 1998. Customer evaluations of service complaint experiences: Implications for relationship marketing. Journal of Marketing, 62(2), pp.60-76. Available at: <Go to ISI>:/ /WOS:000072903200005.

Wagner, J., Bolton, R.N. \& Smith., a. K., 1999. A model of customer satisfaction with service encounters involving failure and recovery. Journal of Marketing Research, 36(3), pp.356-72. 